\title{
Longitudinal Evaluation of Trifocal and Extended Depth of Focus Lenses Implantation using Standard Automated Perimetry Parameters
}

Ricardo Y Abe ( $\nabla$ ricardoabe85@yahoo.com.br)

University of Campinas https://orcid.org/0000-0002-7023-2144

Maíra Gomes Barbosa da Silva

Hospital Oftalmológico de Brasília

Thiago Nogueira Alves

Hospital Oftalmológico de Brasília

Wilson Takashi Hida

Hospital Oftalmológico de Brasília

\section{Research Article}

Keywords: Cataract surgery, Multifocal IOLs, PanOptix IOL, Symfony IOL, Visual performance

Posted Date: January 11th, 2022

DOI: https://doi.org/10.21203/rs.3.rs-1204190/v1

License: (c) (i) This work is licensed under a Creative Commons Attribution 4.0 International License.

Read Full License 


\section{Abstract}

Purpose: To evaluate reliability and global indices parameters from standard automated perimetry (SAP) in normal eyes undergoing phacoemulsification cataract surgery with implantation of trifocal or extended depth of focus intraocular lens (IOL).

Methods: Prospective comparative study. Comparison of trifocal IOL AcrySof IQ PanOptix® and extended depth of focus intraocular lens (EDOF) Tecnis Symfony ${ }^{\circledR}$ IOL. Patients underwent SAP pre- and postoperatively. Reliability indices (false negative rate - FN, false positive rate - FP), global indices (foveal sensitivity threshold, visual field index - VFI, standard pattern deviation - PSD, mean deviation MD) and test duration were analyzed.

Results: A total of 23 eyes from 13 patients were in the trifocal IOL group and a total of 22 eyes from 14 patients were in the EDOF group The following results were obtained by analyzing pre- and postoperative SAP of EDOF IOL: the rate of change of FN was 1.95/1.41\% ( $p=0.61)$; FP 1.64/1.27 ( $p=0.60)$; MD $-1.60 /-1.08 d B(p=0.15)$; foveal sensitivity was 34.5/33.9dB ( $p=0.41)$; VFI 98.5/98.4\% ( $p>0.99) ;$ PSD $1.85 / 1.86(p=0.07) ;$ and for test duration 305.81/298.36s ( $p=0.35)$; all respectively. Analysis of pre- and postoperative parameters of trifocal IOL was: the rates of change of FN 1.22/1.83\% $(p=0.29)$; FP $1.65 / 1.48 \%(p=0.95) ; M D-1.55 /-1.37 d B(p=0.19)$; foveal sensitivity 33.9/34.9dB ( $p=0.47) ; V F I$ 98.6/98.3\% ( $p=0.62) ;$ PSD 1.58/2.05 ( $p=0.02)$; and test duration 297.17/298.57s ( $p=0.87)$; all respectively.

Conclusion: We identified a change in the PSD parameters in the trifocal IOL group. No other significant changes were identified in SAP parameters after implantation of trifocal AcrySof IQ PanOptix ${ }^{\circledR}$ and EDOF Tecnis Symfony ${ }^{\circledR}$ IOL. Longitudinal evaluation showed no changes in SAP after Trifocal and EDOF IOL implantation in normal subjects.

\section{Introduction}

The standard automated computer perimetry (SAP) analyzes the entire scope of peripheral vision ${ }^{1}$, also known as a visual field. It is based on detection of retinal sensitivity at different light intensities ${ }^{2}$. Visual field evaluation in perimetry is used to evaluate several ophthalmological diseases, being a crucial exam that helps to investigate the etiology of the disease. In glaucoma, SAP is essential not only for the diagnosis of the disease but also to monitor the progression of the disease, providing an adequate follow up of the disease 2,3 .

All cataract subtypes may affect contrast sensitivity and visual acuity (VA) ${ }^{4-6}$. Cataracts can alter the several SAP parameters such as total deviation, foveal sensibility and others. ${ }^{7-10}$ Cataract surgery is one of the most performed surgical procedures in the world ${ }^{11}$. The use of intraocular lenses (IOL) aims to provide high-quality vision and reduce the need for additional optical correction ${ }^{12}$. Despite the technology of SAP examination have not presented significant advances in the last years, new IOL technologies such 
as trifocal and extended depth of focus (EDOF) have brought innovation to clinicians and patients, delivering a new range of visual acuity in different distances ${ }^{13,14}$.

Multifocal intraocular lenses were introduced in $1986^{15}$ and have the benefit of promoting, both, near and far vision simultaneously and satisfactorily ${ }^{13}$. Despite the advantages of multifocal lenses, reduction of contrast sensitivity remains a drawback ${ }^{16}$. Some patients still experience visual discomfort, in the form of halos, glares and reduced contrast sensitivity ${ }^{11,17}$. Trifocal IOL is a multifocal IOL designed to provide better intermediate visual acuity without impairing vision from near and far distance ${ }^{18}$. The EDOF IOL represents the new segment of presbyopia correction lenses, designed to lengthen the IOL focus, giving continuous vision from the distance through intermediate and correct chromatic aberration ${ }^{19}$.

There is no evidence in the literature showing that trifocal and EDFI IOLs could impair the performance of SAP examination. Thus, the aim of this study was to quantify, in normal eyes, how trifocal and EDFI lenses could affect the reliability indices (FN, FP), the global indices of the MD, foveal sensibility, VFI, PSD and duration of the test. This data could help the clinician to decide the best IOL option for individualized patients.

\section{Material And Methods}

Prospective study including patient with newly diagnosed senile cataract in one or both eyes, from the Hospital de Brasília - HOB, Brazil, between 2018 and 2020. The study was performed in adherence to the tenets of the Declaration of Helsinki and approved by the approval was granted by the Ethics Committee of The Hospital Oftalmológico de Brasília.

Written informed consent was obtained from all individual participants included in the study. before each surgical procedure. Eyes with a history of trauma or inflammation were excluded, as were eyes with a history of intraocular or laser surgery within the previous 6 months. Additional exclusion criteria were the presence of any media opacities, glaucoma (or suspects of glaucoma) and retinal diseases, which could confound the evaluation.

We included patients that presented indication of phacoemulsification with trifocal IOL (AcrySof IQ PanOptix ${ }^{\circledR}$, Alcon Laboratories, Inc., Fort Worth, TX) or extended depth of focus intraocular lens (EDOF) (Tecnis Symfony ${ }^{\circledR}$, Johnson and Johnson Vision, Jacksonville, FL) implants. Only patients with normal and reliable visual field (VF) examinations were included. VFs were considered reliable if: Fixation loss < $20 \%$, false negative rate $(\mathrm{FN})<33 \%$, False positive rate $(\mathrm{FP})<33 \%$, discarding learning effect. Only patients with best-corrected visual acuity before and after surgery better than 0.2 (logMAR) were included in the study.

All participants underwent a comprehensive ocular examination, which included a detailed medical history, best-corrected visual acuity measurement, slit-lamp biomicroscopy. Additionally, Goldmann applanation tonometry, SAP and retinography for glaucoma. SAP examination was performed in a 
random order (right or left eye to avoid the bias of fatigue) using Humphrey HFA II745 - Zeiss (Humphrey ${ }^{\circledR}$ Field Analyzer, Carl Zeiss Meditec) with Swedish interactive threshold algorithm (SITA) standard 24-2 STANDARD program. Tests were performed up to 3 months before and up to 6 months after the IOL implants. Pre-operative measurements with SAP were performed by experienced certified ophthalmic technicians. The inclusion criteria were patients with reliable perimetry examination prior to surgery, which presented normal exams without the need for re-testing.

Cataract surgeries were performed by a single experienced surgeon (WTH). All patients underwent phacoemulsification with intraocular lens implantation. Only surgeries without intra and post-operative complications were included. Posterior capsulotomy with YAG laser were performed during follow-up at the discretion of the surgeon. The postoperative data was measured at a maximum of 6 months following surgery. Recommendations for using corrective lenses during the test were followed as directed by the device manufacturer.

\section{Statistical analysis}

Descriptive analyses were performed to determine mean, range and standard deviation. To determine if there was significant difference between the reliability indices (FN, FP), global indices (MD, foveal sensibility, VFI, PSD) and test duration, pre- and postoperatively, we used Wilcoxon test. Statistical significance was set at $\mathrm{P}<.05$ and all analyses were done using $\mathrm{R}$ function (R-System, Sacramento, CA).

\section{Results}

The study included 45 eyes from 27 participants, who had an indication of EDOF and trifocal IOLs implantation and underwent SAP examination before and after cataract surgery. A total of 22 eyes from 14 patients were included in the EDOF group and 23 eyes from 13 patients were included in the trifocal IOL group. The mean age of the subjects was $63.2 \pm 5.1$ years. Further reliability indices, global indices and test duration mean comparison between pre-and postoperative are shown in Table 1. 
Table 1

Standard Automated Perimetry Results of Eyes with extended depth of focus (EDOF) and Trifocal Intraocular Lens.

\begin{tabular}{|c|c|c|c|c|c|c|c|c|}
\hline \multirow[t]{2}{*}{ Variable } & \multicolumn{4}{|c|}{ EDOF IOL } & \multicolumn{4}{|c|}{ Trifocal IOL } \\
\hline & $\begin{array}{l}\text { Mean } \\
\text { Pre }\end{array}$ & $\begin{array}{l}\text { Mean } \\
\text { Post }\end{array}$ & $\begin{array}{l}\text { Mean } \\
\text { difference }\end{array}$ & $\begin{array}{l}\text { ap- } \\
\text { value }\end{array}$ & $\begin{array}{l}\text { Mean } \\
\text { Pre }\end{array}$ & $\begin{array}{l}\text { Mean } \\
\text { Post }\end{array}$ & $\begin{array}{l}\text { Mean } \\
\text { difference }\end{array}$ & $\begin{array}{l}\text { ap- } \\
\text { value }\end{array}$ \\
\hline FN (\%) & 1.95 & 1.41 & $0.25 \pm 3.75$ & 0.61 & 1.22 & 1.83 & $\begin{array}{l}-1.00 \pm \\
2.50\end{array}$ & 0.29 \\
\hline FP (\%) & 1.64 & 1.27 & $0.50 \pm 1.50$ & 0.60 & 1.65 & 1.48 & $0.25 \pm 1.75$ & 0.95 \\
\hline $\mathrm{MD}(\mathrm{dB})$ & -1.60 & -1.08 & $0.52 \pm 0.71$ & 0.15 & -1.55 & -1.37 & $\begin{array}{l}-0.19 \pm \\
0.48\end{array}$ & 0.19 \\
\hline $\begin{array}{l}\text { FOVEA } \\
\text { (dB) }\end{array}$ & 34.5 & 34.8 & $\begin{array}{l}-0.25 \pm \\
0.75\end{array}$ & 0.41 & 33.9 & 34.9 & $0.25 \pm 1.25$ & 0.47 \\
\hline VFI (\%) & 98.5 & 98.4 & $0.25 \pm 1.25$ & $>0.99$ & 98.6 & 98.3 & $0.25 \pm 1.25$ & 0.62 \\
\hline PSD (dB) & 1.85 & 1.86 & $\begin{array}{l}-0.50 \pm \\
0.57\end{array}$ & 0.07 & 1.58 & 2.05 & $\begin{array}{l}-0.35 \pm \\
0.39\end{array}$ & 0.02 \\
\hline $\begin{array}{l}\text { Test } \\
\text { duration (s) }\end{array}$ & 305.81 & 298.36 & $\begin{array}{l}7.75 \pm \\
18.25\end{array}$ & 0.35 & 297.17 & 298.57 & $0.00 \pm 12.5$ & 0.87 \\
\hline \multicolumn{9}{|c|}{$\begin{array}{l}\text { Pre= preoperative. Post }=\text { postoperative. } \mathrm{FN}=\text { false negative rate. } \mathrm{FP}=\text { false positive rate. FOVEA }= \\
\text { foveal sensitivity threshold. VFI= visual field index }-\mathrm{VFI} . \mathrm{PSD}=\text { pattern standard deviation. } \mathrm{MD}= \\
\text { mean deviation. } \mathrm{IOL}=\text { intraocular lens; } \mathrm{SD}=\text { standard deviation. \%= percentage. } \mathrm{s}=\text { seconds. } \mathrm{dB}= \\
\text { decibel. }\end{array}$} \\
\hline
\end{tabular}

The pre and postoperative mean of FN by SAP of EDOF IOL as a percentage was 1.95/1.41\%, respectively. The mean of FP was $1.64 / 1.27 \%$, respectively. The mean of MD in decibel (dB) was $-1.6 /-1.08 \mathrm{~dB}$, respectively. The mean of fovea sensibility was $34.5 / 34.8 \mathrm{~dB}$, respectively. The mean of VFI was $98.5 / 98.4 \%$, respectively. The mean of PSD was $1.8 / 1.86 \mathrm{~dB}$, respectively. The mean of test duration in seconds (s) was $305.81 / 298.36 \mathrm{~s}$, respectively. For trifocal IOLs, the mean of FN, pre-and postoperative, by SAP was $1.22 / 1.83 \%$, respectively. The mean of FP was $1.65 / 1.48 \%$, respectively. The mean of MD in decibel $(\mathrm{dB})$ was $-1.55 /-1.37 \mathrm{~dB}$, respectively. The mean of fovea sensibility was $33.9 / 34.9 \mathrm{~dB}$, respectively. The mean of VFI was $98.6 / 98.3 \%$, respectively. The mean of PSD was $1.85 / 1.58 \mathrm{~dB}$, respectively. The mean of test duration in seconds (s) was $297.17 / 298.57 \mathrm{~s}$, respectively.

The mean difference of FN in eyes with EDOF IOL was $0.25 \pm 3.75 \%$, and the trifocal IOL was $-1.00 \pm$ $2.50 \%$. The mean difference of FP in the eyes with EDOF IOL was $0.50 \pm 1.50 \%$, and the trifocal IOL was $0.25 \pm 1.75 \%$. The mean difference of MD in the eyes with EDOF IOL was $0.52 \pm 0.71 \mathrm{~dB}$, and the trifocal IOL was $-0.19 \pm 0.48 \mathrm{~dB}$. The mean difference of fovea sensibility in the eyes with EDOF IOL was $-0.25 \pm$ $0.75 \mathrm{~dB}$, and the trifocal IOL was $0.25 \pm 1.25 \mathrm{~dB}$. trifocal mean difference of VFI in the eyes with EDOF 
IOL was $0.25 \pm 1.25 \%$, and the trifocal IOL was $0.25 \pm 1.25 \mathrm{~dB}$. The mean difference of PSD in the eyes with EDOF IOL was $-0.50 \pm 0.57 \%$, and the trifocal IOL was $-0.35 \pm 0.39 \mathrm{~dB}$. The mean difference of test duration in the eyes with EDOF IOL was $7.75 \pm 18.25 \mathrm{~s}$, and the trifocal IOL was $0.00 \pm 12.5 \mathrm{~s}$.

The PSD difference of trifocal lens preoperative was statistically significant and lower than postoperative $(P=0.02)$. No factors were statistically significant associated with changes in $F N, F P, M D$, fovea sensibility, $\mathrm{VFI}$ and test duration.

\section{Discussion}

In this study, we used SAP to assess reliability indices, global indices, and test duration of EDOF and trifocal IOLs. Recently, the use of trifocal and EDOF lenses have been showing better contrast responses ${ }^{4,20}$ with lower incidence of halos compared to previous multifocal IOL. Thus, it is important to investigate if the implantation of these IOL may alter the ability of a normal individual to perform the SAP examination. We found that only the PSD in the trifocal group presented statistically changes pre and post cataract surgery. None of the other parameters presented significant changes.

In the present study, we included only patients that presented reliable visual fields before surgery and those who performed a reliable test with a single examination before surgery to avoid that a possible learning effect could affect the SAP results after cataract surgery. We quantified the effects the reliability indices may have on the VF results, as well as the MD and PSD, which are important summary values that can be used to indicate severity of VF defects and to track visual function loss. To our knowledge, there are no studies comparing visual field parameters after trifocal or EDFI IOLs implantation, in a longitudinal design.

Several other studies have investigated the use of multifocal IOLs in a cross-sectional design. A previous study did show that multifocal IOL reduces the retinal sensitivity in the SAP test ${ }^{21}$. The study concluded that such reduction seems to be related to the multifocal design of the IOLs rather than to cataract surgery alone ${ }^{21}$. Another study showed that there was no difference in frequency doubling technology (FDT) matrix perimetry results in eyes that received an apodized diffractive IOL implant, or eyes that received monofocal IOL implantation ${ }^{22}$. While Kang and Lee et al, found a significant difference between multifocal IOLs and monofocal IOLs using Goldmann kinetic perimetry ${ }^{17}$, the studies diverge as to the variation caused by IOL in the patients visual field ${ }^{17,22}$. All of the previous studies compared others multifocal IOLs but none of them have compared the performance of trifocal and EDOF IOLs.

In glaucoma, SAP exam is necessary to classify the stage of disease and to monitor visual function to detect progression of the disease. There have been many studies regarding cataract extraction's impact on visual field in glaucoma patients. Those studies have demonstrated that visual field parameters (MD and PSD) can improve following cataract extraction. MD was shown to improve after cataract surgery in most studies. Concerning PSD values, the data is not so consistent; some studies have shown no change in PSD postoperatively, while others have demonstrated deterioration of PSD ${ }^{23}$. In fact, we also found 
postoperative worsening of PSD after AcrySof IQ PanOptix ${ }^{\circledR}$ IOL implantation in normal eyes, even though none of these values were recorded as outside normal limits when comparing to the database, suggesting that the change was not clinically significant.

This study has several limitations. First, the lack of a sample size calculation prior to the study to determine the significance of the results limit this data to a descriptive analysis rather than a robust finding. Second, the inclusion of normal individuals without any eye diseases, such as glaucoma, does not allow the extrapolation of the results to a population with confirmed glaucoma, glaucoma suspects and any other ocular diseases. However, demonstrating that the implant of these lenses does not alter parameters of SAP is the initial step in investigating these alterations in other populations. Third, the inclusion of both eyes from most patients were not ideal since measurements obtained from right and left eyes are usually correlated, however we used Wilcoxon test with non-parametric analysis which minimizes this bias. Finally, we only included patients that were able to perform the initial SAP exam before the cataract surgery without the need of repeating the test. Therefore, these results may not be extended to those patients that present unreliable exams and need to repeat the SAP exam.

\section{Conclusion}

In conclusion, the present study demonstrated that there were no significant changes in SAP parameters following the implantation of both AcrySof IQ PanOptix ${ }^{\circledR}$ IOL and Symfony IOL in normal subjects. However, a larger sample size study is needed to correlate if there is long-term variability in perimetry examination, and consequently in visual field of patients after trifocal and EDOF IOLs implantation. To date, this is the first study to evaluated longitudinally SAP parameters using trifocal AcrySof IQ PanOptix ${ }^{\circledR}$ and extended depth of focus (EDOF) Tecnis Symfony ${ }^{\circledR}$ IOL. No significant changes were observed after the implantation of these IOLs.

\section{Declarations}

\section{Compliance with Ethical Standards}

The authors declare that no funds, grants, or other support were received during the preparation of this manuscript.

The authors have no relevant financial or non-financial interests to disclose.

All procedures performed in studies involving human participants were in accordance with the ethical standards of the institutional and/or national research committee and with the 1964 Helsinki declaration and its later amendments or comparable ethical standards.

Informed consent was obtained from all individual participants included in the study 


\section{Authors Contributions}

All authors contributed to the study conception and design. Material preparation, data collection and analysis were performed by RYA,MGBS, TNA, PFMT and WTH. The first draft of the manuscript was written by RYA and MGBS and all authors commented on previous versions of the manuscript. All authors read and approved the final manuscript.

\section{Financial Support:}

None.

\section{Conflict of Interest:}

No conflicting relationship exists for any authors.

\section{References}

1. Heijl A (1985) Computerised perimetry. Transactions of the ophthalmological societies of the United Kingdom 104(Pt 1):76-87

2. Eagleman DM, Jacobson JE, Sejnowski TJ (2004);428(Perceived luminance depends on temporal context. Nature Apr 22(6985):854-856. doi:10.1038/nature02467

3. Hawken MJ, Blakemore C, Morley JW (1997) Development of contrast sensitivity and temporalfrequency selectivity in primate lateral geniculate nucleus. Experimental brain research Mar 114(1):86-98. doi:10.1007/pl00005626

4. Vilar C, Hida WT, de Medeiros AL et al (2017) Comparison between bilateral implantation of a trifocal intraocular lens and blended implantation of two bifocal intraocular lenses. Clin Ophthalmol 11:1393-1397

5. Shandiz JH, Derakhshan A, Daneshyar A et al (2011) Effect of cataract type and severity on visual acuity and contrast sensitivity. Journal of ophthalmic \& vision research Jan 6(1):26-31

6. Lam BL, Alward WL, Kolder HE Effect of cataract on automated perimetry. Comparative Study Ophthalmology (Jul 1991);98(7):1066-70. doi:10.1016/s0161-6420(91)32175-4

7. Lee J, Mori Y, Nejima R, Minami K, Miyata K (2020);10(Influence of implantations of extended depthof-focus on standard automated perimetry. Scientific reports Nov 19(1):20153. doi:10.1038/s41598020-77214-8

8. Tan NYQ, Tham YC, Koh V et al (2018) The Effect of Testing Reliability on Visual Field Sensitivity in Normal Eyes: The Singapore Chinese Eye Study. Ophthalmology Jan 125(1):15-21.

doi:10.1016/j.ophtha.2017.08.002 
9. Jang SY, Ohn YH, Kim SW (Aug 2010) Effect of yellow-tinted intraocular lenses on short-wavelength automated perimetry. American journal of ophthalmology. ;150(2):243-247 e1. doi:10.1016/j.ajo.2010.02.023

10. Castro LC, de Souza CE, Soriano ES, Melo LA Jr, Paranhos A Jr (2006) Influence of blue light spectrum filter on short-wavelength and standard automated perimetries. Arquivos brasileiros de oftalmologia. Sep-Oct 69(5):725-729. doi:10.1590/s0004-27492006000500020

11. Day AC, Gore DM, Bunce C, Evans JR (2016) Laser-assisted cataract surgery versus standard ultrasound phacoemulsification cataract surgery. The Cochrane database of systematic reviews Jul 8 7:CD010735. doi:10.1002/14651858.CD010735.pub2

12. Auffarth GU, Hunold W, Breitenbach S, Wesendahl TA, Mehdorn E (1993) Long-term results of contrast perception and glare sensitivity in patients with diffraction multifocal lenses. Klinische Monatsblatter fur Augenheilkunde Nov 203(5):336-340. doi:10.1055/s-2008-1045687

13. Rampat R, Gatinel D (2020) Multifocal and Extended Depth-of-Focus Intraocular Lenses in 2020. Ophthalmology Sep 25. doi:10.1016/j.ophtha.2020.09.026

14. Breyer DRH, Kaymak H, Ax T, Kretz FTA, Auffarth GU, Hagen PR (Multifocal Intraocular Lenses and Extended Depth of Focus Intraocular Lenses. Asia Pac J Ophthalmol (Phila). Jul-Aug 2017) ;6(4):339-349. doi:10.22608/AP0.2017186

15. Keates RH, Pearce JL, Schneider RT (1987) Clinical results of the multifocal lens. Journal of cataract and refractive surgery Sep 13(5):557-560. doi:10.1016/s0886-3350(87)80114-1

16. Mesci C, Erbil HH, Olgun A, Aydin N, Candemir B, Akçakaya AA (2010) Differences in contrast sensitivity between monofocal, multifocal and accommodating intraocular lenses: long-term results. Clin Exp Ophthalmol 38(8):768-777

17. Kang SG, Lee JH (1994) The change of visual acuity and visual field by diminished illumination in eyes with multifocal intraocular lens. Korean J Ophthalmol 8(2):72-76

18. Voskresenskaya A, Pozdeyeva N, Pashtaev N, Batkov Y, Treushnicov V, Cherednik V (2010) Initial results of trifocal diffractive IOL implantation. Graefe's archive for clinical and experimental Sep 248(9):1299-1306. doi:10.1007/s00417-010-1424-8

19. Ruiz-Alcocer J, Lorente-Velazquez A, Hernandez-Verdejo JL, De Gracia P, Madrid-Costa D (2020) ;36(Optical Performance of a Trifocal IOL and a Novel Extended Depth of Focus IOL Combined With Different Corneal Profiles. J Refract Surg Jul 1(7):435-441. doi:10.3928/1081597X-20200519-02

20. Mencucci R, Favuzza E, Caporossi O, Savastano A, Rizzo S (2018) Comparative analysis of visual outcomes, reading skills, contrast sensitivity, and patient satisfaction with two models of trifocal diffractive intraocular lenses and an extended range of vision intraocular lens. Graefe's archive for clinical and experimental ophthalmology Oct 256(10):1913-1922. doi:10.1007/s00417-018-4052-3

21. Aychoua N, Junoy Montolio FG, Jansonius NM (2013) Influence of multifocal intraocular lenses on standard automated perimetry test results. JAMA ophthalmology Apr 131(4):481-485. doi:10.1001/jamaophthalmol.2013.2368 
22. Bojikian KD, Vita JB, Dal Forno CP, Tranjan Neto A, Moura CR (2009) Does the apodized diffractive intraocular lens Acrysof ReSTOR Natural interfere with FDT Matrix perimetry results? Arquivos brasileiros de oftalmologia. Nov-Dec 72(6):755-759. doi:10.1590/s0004-27492009000600003

23. Koucheki B, Nouri-Mahdavi K, Patel G, Gaasterland D, Caprioli J (2004) Visual field changes after cataract extraction: the AGIS experience. American journal of ophthalmology Dec 138(6):10221028. doi:10.1016/j.ajo.2004.08.006

\section{Supplementary Files}

This is a list of supplementary files associated with this preprint. Click to download.

- PLANILHAMODIFICADA2.xIsx 